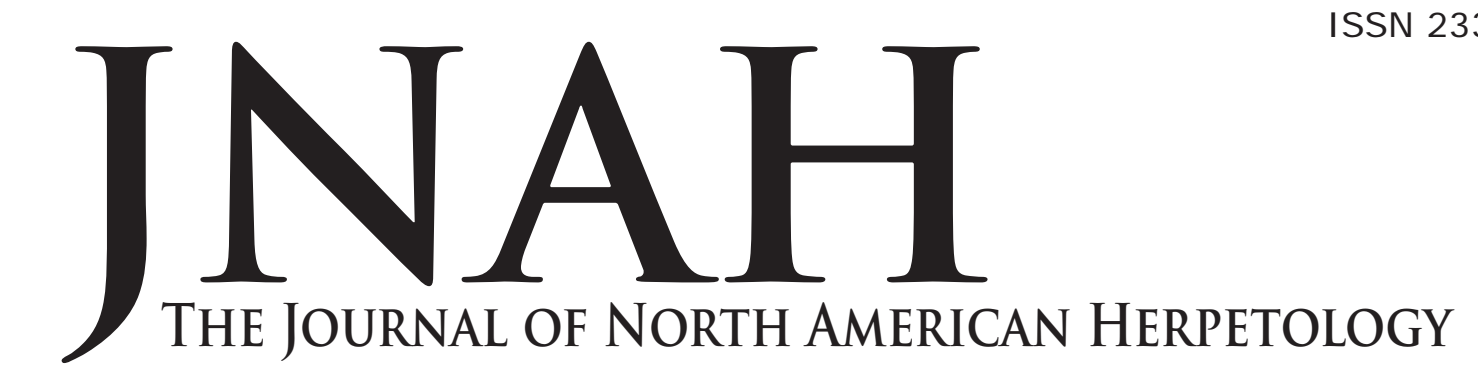

Volume 2015(1): 6-11

1 May 2015

jnah.cnah.org

\title{
NATURAL HISTORY AND MERISTICS OF AN ALLOPATRIC POPULATION OF RED CORNSNAKES, PANTHEROPHIS GUTTATUS (LINNAEUS, 1766) IN CENTRAL KENTUCKY, USA
}

\author{
WILLIAM M. BIRD ${ }^{1,2,3}$, PHILIP PEAK², AND DANNA L. BAXLEY4,5 \\ ${ }^{1}$ Department of Biological Sciences, Indiana University Southeast, 4201 Grant Line \\ Road, New Albany, IN 47150 \\ ${ }^{2}$ Kentucky Herpetological Society, Louisville, KY 40272 \\ ${ }^{3}$ Louisville Zoo and Botanical Gardens, 1100 Trevillian Way, Louisville, KY 40223. \\ ${ }^{4}$ Kentucky Department of Fish and Wildlife Resources, \#1 Sportsman's Lane, Frank- \\ fort, KY 40601 \\ ${ }^{5}$ Corresponding Author - danna.baxley@ky.gov
}

\begin{abstract}
Life history, morphological variation, and basic biology of Pantherophis guttatus (Linnaeus, 1766), the Red Cornsnake, are not well known, particularly for the allopatric populations in Kentucky. To address some of the information gaps for this species, we report field observations, including activity patterns, reproduction, and meristics of P. guttatus in Kentucky. In 2003 and 2004 we conducted field surveys using drift fences, artificial cover, manual searching, and driving on roads and captured 101 P. guttatus in Edmonson and Hart counties, Kentucky. We found that artificial cover was the best method of detection with $77 \%$ of snakes captured using this method. Numbers of encounters peaked in April-May and August-September suggesting bimodal activity patterns similar to other colubrid snakes. Males had significantly higher subcaudal scale counts than females while females had significantly higher ventral scale counts than males. We detected more individuals in 2003 than in 2004, most likely influenced by severe drought conditions in Kentucky during 2004. Size-class distribution of snakes was skewed towards large individuals (> $70 \mathrm{~cm} \mathrm{SVL}$ ). The absence of individuals in juvenile size classes $(30 \mathrm{~cm}-70 \mathrm{~cm}$ ) may be an artifact of lower detection probabilities for smaller size classes, different habitat use by juveniles, or may indicate low recruitment.
\end{abstract}

\section{INTRODUCTION}

Pantherophis guttatus (Linnaeus, 1766), the Red Cornsnake, occurs throughout the southeastern United States from Florida west to eastern Louisiana, northward to Tennessee and North Carolina, and in more isolated populations in Kentucky and as far north as southern New Jersey (Conant and Collins 1998) (Figure 1). Despite conservation concern for this species, there is a lack of comprehensive natural history data, particularly for the two isolated populations in Kentucky. The majority of published P. guttatus studies were limited to laboratory experiments (Weldon et al. 1989, Holtzman et al. 1999, Smith 1976) and occurrence records resulting from surveys (Enge and Wood 2002, Tuberville et al. 2005). Although P. guttatus was first described in 1766, the two isolated populations in Kentucky were discovered much later (Hibbard 1936, Chenoweth 1949). Subsequent to these observations, Collins (1970) reported five records from Edmonson, Barren, Hart, Powell, and Menifee counties and suggested P. guttatus in Kentucky comprise two allopatric populations separated by approximately $225 \mathrm{~km}$. Since its documen- tation in Kentucky, P. guttatus has been widely viewed as both rare and difficult to detect within the Commonwealth (Kentucky's Comprehensive Wildlife Conservation Strategy 2005).

There is a paucity of information regarding life history, morphological variation, and basic biology of P. guttatus. This lack of information is particularly problematic since it is a species of conservation concern in Kentucky and its systematic status is controversial. Within the past decade, P. guttatus has been split into three distinct geographic lineages based on mitochondrial DNA analysis (Burbrink 2002), has been placed in the genus Pantherophis (Utiger et al. 2002), and then moved to the genus Pituophis (Burbrink and Lawson 2007). Subsequently, Collins and Taggart (2008) argued against the placement of cornsnakes in the genus Pituophis and suggested an alternative classification favoring Pantherophis as the accepted genus. Aside from Meade's (2005) collection of meristic data ( $n=18$ ) in Kentucky, little information is available regarding morphological variation in P. guttatus. In addition, natural history information from field observations 
is severely lacking in Kentucky. To address some of the information gaps in the central Kentucky population we sought to expand upon existing information by reporting natural history observations including: activity patterns, reproduction, and meristics. Our study included an extreme drought year; consequently, we hypothesized that decreased P. guttatus surface activity would be associated with drought conditions of 2004. This species is currently listed as a Species of Greatest Conservation Need (Kentucky's Comprehensive Wildlife Conservation Strategy 2005) in Kentucky and is of conservation concern elsewhere (e.g., considered "critically imperiled" in New Jersey and Delaware; NatureServe 2008); consequently, natural history and meristic studies are warranted.

Study Area - Our study area was comprised of Edmonson and Hart counties, Kentucky (Figure 1), located within the Mississippian Plateau physiographic region and representing a total area of approximately 188,033 ha. The study area includes Mammoth Cave National Park whose 21,382 ha are located primarily in Edmonson County. This physiographic region is rich in karst topography and is bounded to the west by the Dripping Springs Escarpment and to the north by Muldraughs Hill. An un-impounded section of the Green River bisects the study area. Mammoth Cave National Park is characterized almost exclusively by deciduous forests, while the remainder of the study area is characterized by a mixture of deciduous forests, pasture/hay lands, and cultivated crops. Very little developed area exists in these counties. The largest developed area is Mundfordville (population 1,563 at the 2000 census), which is approximately 269 ha in size.

\section{METHODS}

Survey Techniques - From January 2003 to December 2004 we employed standard herpetological survey techniques (Gibbons and Semlitsch 1981, Campbell and Christman 1982, Fitch 1987) in Hart and Edmonson counties (Figure 1) to detect P. guttatus in Kentucky. Tech- niques included driving on roads, manual search efforts (particularly at road-side dumps and old house sites), drift fences with funnel traps ( 3 trap arrays), and artificial cover sites (comprised mainly of metal and wooden cover boards; 300 pieces total). Artificial cover was opportunistically placed to provide a variety of thermoregulatory opportunities to snakes; for example, some pieces were situated to receive sunlight while others were in partial or full shade. To minimize disturbance to artificial cover sites we used discretion when checking them by flipping artificial cover only when temperatures seemed appropriate for snakes $\left(4.0^{\circ} \mathrm{C}-33^{\circ} \mathrm{C}\right)$. Once established, artificial cover was allowed to "season" for two months prior to the first survey visit to the site. Drift fences and box-style funnel traps $(122 \mathrm{~cm} \times 122 \mathrm{~cm}$, built of treated lumber and galvanized wire similar to those described by Burgdorf et al. 2005) were employed at three sites. Funnel traps were paired with four $15 \mathrm{~m}$ lengths of black silt fence radiating from each side of the box; no satellite traps (at the ends of fences) were employed. To minimize mortality of herpetofauna a water container and elevated hide platform were placed within each trap. Whenever possible we sought to position traps in transitional habitat areas representing "edge" habitat between field and forest. Sites were visited a minimum of once per week from J anuary to December 2003 and 2004, and traps and artificial cover were checked at a wide variety of times (e.g., early morning, mid-afternoon, late evening). We did not document total effort using each sampling technique across years, nor did we record total road-searching hours, total manhours or total trap nights for our study.

Collection of Meristic and Natural History Data - Collection of meristic data was not an initial goal of our study; however, during the initial phases of our project we noticed differences in blotches and scale rows among individual snakes. As a result we began collecting meristic data partway through the study, with data collected from 59 of 101 individuals. The measurements collected in-

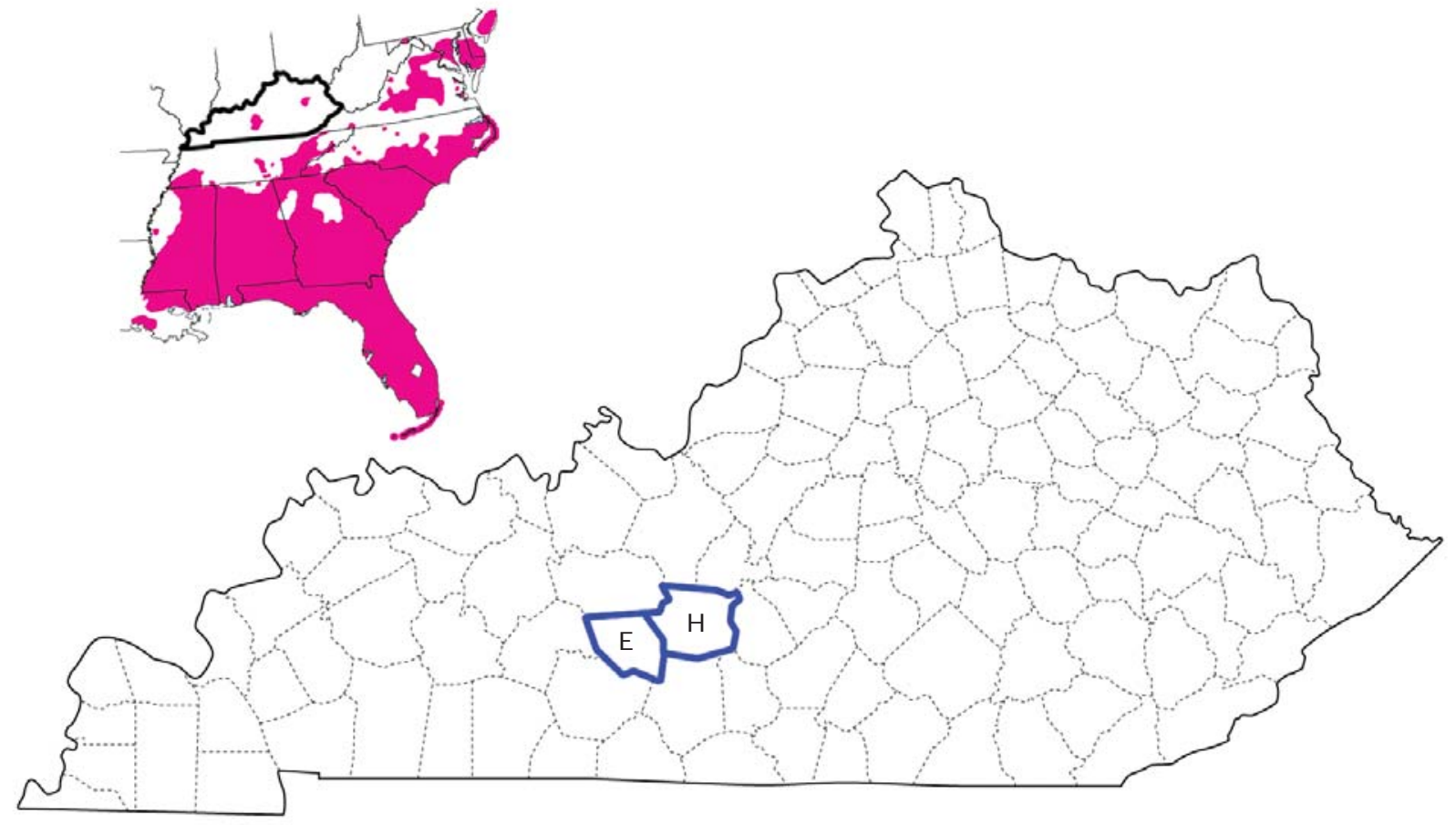

Figure 1. Study Area where Red Cornsnake (Pantherophis guttatus) surveys were conducted in 2003 and 2004. Hart (H) and Edmonson (E) counties, Kentucky are indicated in bold. 
Table 1. Meristic data for Red Cornsnakes (Pantherophis guttatus) from Hart and Edmonson counties, Kentucky.

\begin{tabular}{|c|c|c|c|c|c|}
\hline & Mean & $\begin{array}{r}\text { Standard } \\
\text { error }\end{array}$ & $\mathrm{n}$ & Min & $\operatorname{Max}$ \\
\hline Dorsal body blotches & 30.5 & 0.28 & 41 & 27 & 34 \\
\hline Caudal blotches & 11.8 & 0.40 & 26 & 11 & 15 \\
\hline Nape scale rows & 25.0 & 0.16 & 30 & 23 & 27 \\
\hline Mid-body scale rows & 27.0 & 0.09 & 59 & 26 & 30 \\
\hline Vent scale rows & 19.0 & 0.18 & 27 & 18 & 21 \\
\hline Ventral scale count & 217.0 & 0.94 & 31 & 208 & 229 \\
\hline Subcaudal scale count & 66.0 & 1.82 & 26 & 63 & 74 \\
\hline
\end{tabular}

clude: snout-to-vent dorsal blotch count, mid-body dorsal scale row count (Dowling 1951), caudal blotches, nuchal scale rows, vent scale rows, subcaudal scales, and ventral scale counts (both body and subcaudal). Dorsal body blotch count began with the first dorsal blotch on the nape and terminated at the vent, if a blotch fell directly over the vent, it was counted. Caudal blotches were counted starting from the vent and proceeding to the tip of the tail; data were not collected from individuals with missing tail tips. Blotches falling over the vent were not included in the caudal count. Nuchal scale rows were taken one head length back from the base of the cranium, and vent scale rows were taken two scale rows anterior to the vent (Dowling 1951). We report all body length measurements as snout-to-vent-length (SVL). Because this population is isolated and its conservation status is unknown, we collected as much data as possible from captured individuals, photographed them so that recaptures could be recognized, then released each snake at the point of capture. In addition to meristic data collection we noted the presence or absence of a complete spear marking on the head of each individual, and we opportunistically recorded natural history observations. Lastly, we collected gravid females and held them in captivity until oviposition to obtain reproductive information (e.g., clutch size, hatchling size, incubation duration of eggs). Eggs were placed in plastic Sterlite ${ }^{\circledR}$ shoe boxes with moistened perlite and exposed to a temperature gradient defined by a daytime high of $31^{\circ} \mathrm{C}$ and a nighttime low of $23^{\circ} \mathrm{C}$.

To assess relationships between precipitation, ambient temperature and surface activity and encounter rates, we used climatic data available from the University of Kentucky's Bardstown weather station (available: http://wwwagwx.ca.uky.edu/cgi-bin/ky clim data www.pl). This station is located less than $81 \mathrm{~km}$ from our central study area in Hart and Edmonson counties.

We used J MP version 5.1 (SAS I nstitute, Inc., Cary, North Carolina, 2003) to assess differences in subcaudal and ventral scale counts in male and female snakes and to compare encounter rates across survey years. Assumptions of normality and equal variances were assessed for each data set and appropriate non-parametric or parametric tests were subsequently used (alpha $=0.05$ for all tests). We used a 1-tailed Wilcoxon matched-pairs test to assess yearly differences in the number of $P$. guttatus captured and Chi Square tests to assess differences in scale counts between males and females.

\section{RESULTS}

In total we observed 101 P. guttatus in 2003 and 2004. In 2003, we found 44 live and 15 dead on the road (DOR) (Figure 2). Of the live snakes three were collected in traps, one was found while manually searching, and the remaining 40 were under artificial cover. Similarly, we observed 42 total P. guttatus in 2004: 38 under artificial cover, one alive on the road (AOR) and three DOR. The average number of snakes observed per month between March and November was greater in 2003 than in 2004 $(2003=6.6 ; 2004=4.7)$.

We observed P. guttatus in Kentucky from March through November; no snakes were observed in December, January, or February (Figure 2). May 2003 and May 2004 were the months with the greatest number of total sightings. Average monthly temperatures for these two months were $18.1^{\circ} \mathrm{C}$ and $21.0^{\circ} \mathrm{C}$ respectively (Figure 3 ); peaks in monthly snake observations appear to closely follow precipitation peaks (Figure 4). Our survey data indicate that $P$. guttatus in Kentucky has a bimodal peak in activity (April-May and August-September). On 28 March 2004 we observed our earliest emergence, an adult male under artificial cover. This snake had recently fed, and the ambient temperature was $9.4^{\circ} \mathrm{C}$. The latest observation occurred under artificial cover on 23 November 2003 . The largest adult individual observed was $132 \mathrm{~cm} \mathrm{SVL}$ and the size class distribution (Figure 5) was dominated by larger snakes ( $>70 \mathrm{~cm} \mathrm{SVL}$ ), with no representation of individuals smaller than $71 \mathrm{~cm}$ SVL.

Throughout this study we recorded a number of reproductive observations. On 14 April 2003 an adult male and adult female were discovered under the same piece of artificial cover alongside of each other, although we cannot conclusively say these individuals mated. Three gravid females were collected from Hart County (collected on 2 June, 14 J une, and 14 April) that deposited 9, 12, and14 eggs on 27 June, 21 June, and 26 J une respectively. Two wild collected female snakes bred in captivity and each deposited 10 eggs (thus, the average number of eggs for five clutches was 10.8). Hatching success for clutches was $100 \%$, and incubation time for eggs ranged from 6878 days (average of 70.4 days). Average total length of hatchlings was $37.6 \mathrm{~cm}$.

Several DOR individuals were discovered with empty stomachs, and one recently collected individual passed fecal material containing rodent hair. While we were unable to observe P. guttatus feeding, we did note a number of commensal burrow animals. The most common rodent observed using $P$. guttatus refugia was Microtus pinetorum (LeConte, 1830), the Pine Vole. Other small mammals observed in the same burrows as $P$. guttatus were Blarina brevicauda (Say, 1823), the Short-tailed Shrew, and Peromyscus sp. (mice). Plestiodon fasciatus (Linnaeus, 1758), the Common Five-lined Skink, Scincella lateralis (Say in James, 1823), the Little Ground Skink, and Ophisaurus attenuatus (Cope, 1880), the Slender Glass Lizard were also observed in the same burrows as P. guttatus. Snake species found above ground under the

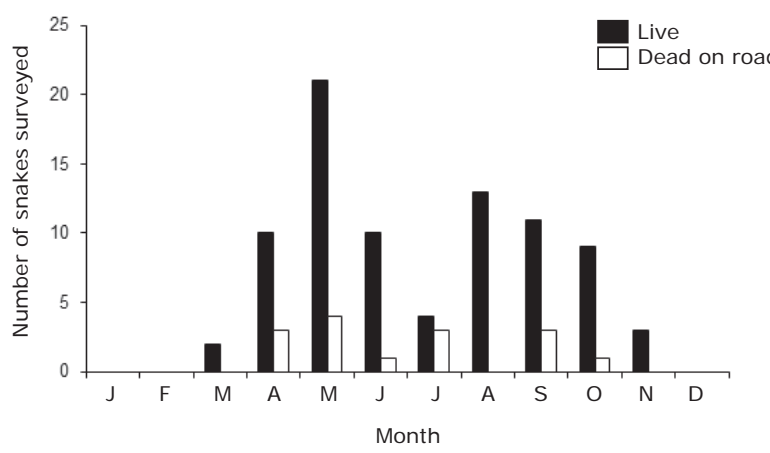

Figure 2. Total number of live and dead on road Red Cornsnakes (Pantherophis guttatus) observed monthly in Hart and Edmonson counties, Kentucky, 2003-2004. 


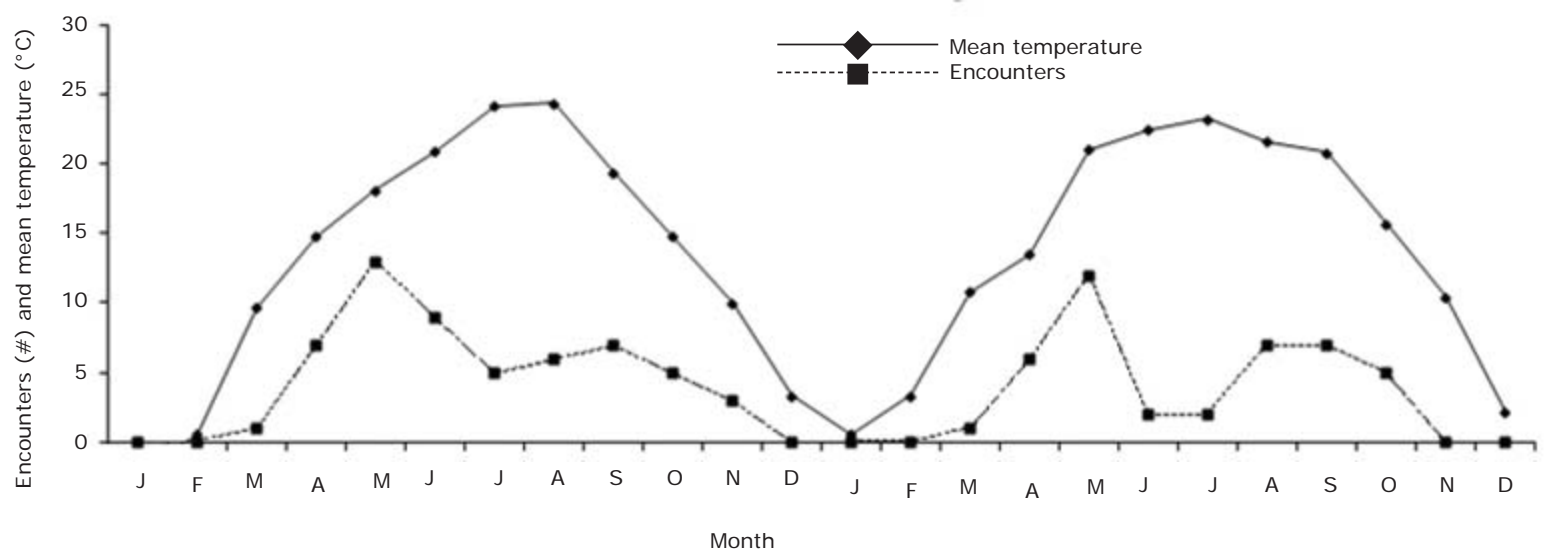

Figure 3. Mean temperature and number of Red Cornsnakes (Pantherophis guttatus) encountered from January 2003 through December 2004.

same piece of artificial cover with $P$. guttatus included the following species: Diadophis punctatus (Linnaeus, 1766), Ring-necked Snake, Storeria dekayi (Holbrook, 1842), Dekay's Brown Snake, Storeria occipitomaculata (Storer, 1839), Red-bellied Snake, Carphophis amoenus (Say 1825), Common Wormsnake, Virginia valeriae (Baird and Girard, 1853), Smooth Earthsnake, Pantherophis spiloides (Say in James 1823), Gray Ratsnake, Heterodon platirhinos (Latreille, 1801), Eastern Hog-nosed Snake, Lampropeltis triangulum (Lacepede, 1789), Eastern Milk Snake, Lampropeltis nigra (Linnaeus, 1766), Black Kingsnake, Lampropeltis calligaster (Harlan, 1827), Yellowbellied Kingsnake, Agkistrodon contortrix (Linnaeus, 1766), Copperhead, and Crotalus horridus (Linnaeus, 1758), Timber Rattlesnake.

Meristic data were collected from 59 individuals, and sample sizes, means, standard error, and ranges are presented in Table 1 for the following characteristics: midbody scale rows, dorsal body blotches, nape scale rows, vent scale rows, ventral scale counts, subcaudal scale counts, and caudal blotches. Of more than 100 total individuals observed in our study, only three (3\%) did not have the classic spear-point marking on the head. Female snakes had significantly more ventral scales than males (mean of 223 versus $214 ; \mathrm{T}_{18}=5.63, \mathrm{P}<0.001$ ). In contrast, male snakes had more subcaudal scales than fe- males (mean of 66.4 for males versus 64.8 for females); these differences were also significant $\left(X^{2}{ }_{9,15}=4.52, P=\right.$ $0.03)$.

\section{DISCUSSION}

The results of this study corroborated previous work pertaining to meristics of P. guttatus (Thomas 1974, Mitchell 1977) and supplement the existing body of knowledge regarding its natural history, particularly in relation to seasonal activity patterns and reproduction. In this study, artificial cover was the best detection method, with 78 snakes ( $77 \%$ of total) detected. The lower encounter rate in 2004 was not surprising given the severe drought conditions in central Kentucky during that year. Although survey efforts in 2003 and 2004 were similar, more snakes were encountered in 2003 than 2004, particularly in the peak activity months of September and J une. Both precipitation and temperature patterns appear to be correlated with activity (Figure 3 and Figure 4). September 2004 was the second-driest month ever recorded in Jefferson County, Kentucky $(0.23 \mathrm{~cm}$ precipitation; NOAA, 2005), and we found no DOR P. guttatus that month, suggesting a lack of surface activity during the drought. It appears that precipitation provides a stimulus for $\mathrm{P}$. guttatus to leave sheltered areas and actively crawl on the surface. It is worth noting that our most productive survey site in

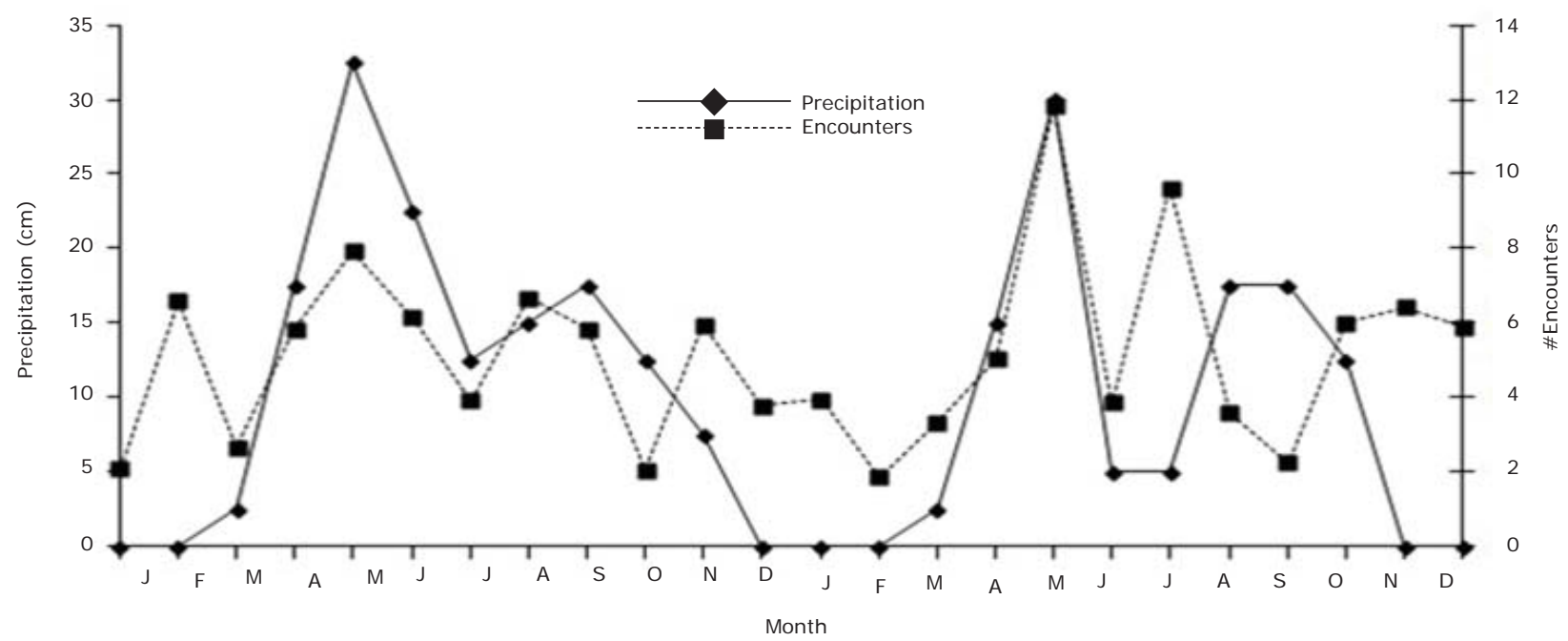

Figure 4. Average monthly precipitation and number of Red Cornsnake (Pantherophis guttatus) encounters from March 2003 through October 2004. 


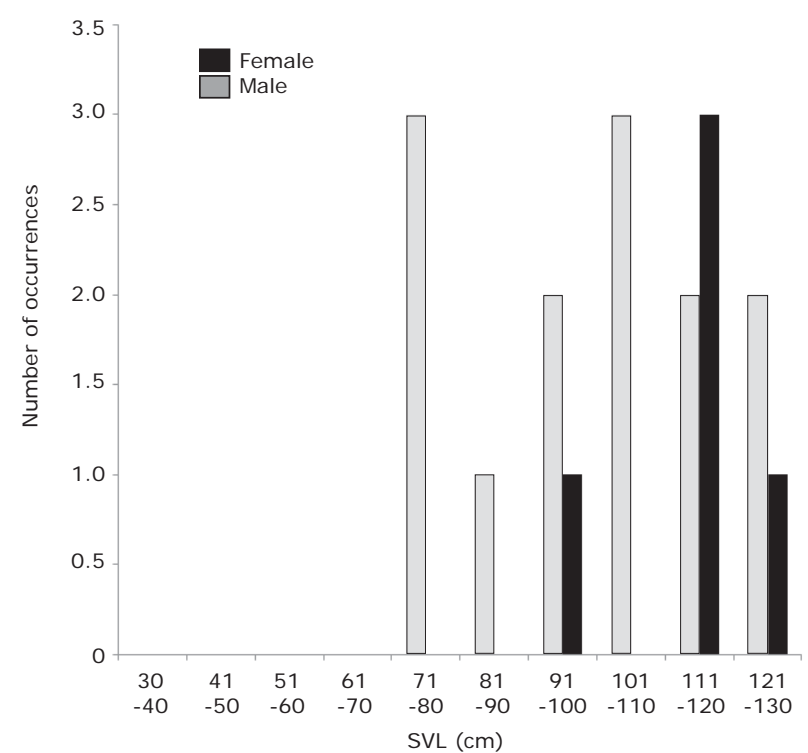

Figure 5. Frequency distribution of size classes of P. guttatus in Hart and Edmonson counties, Kentucky, 2003-2004

2003 did not yield a single P. guttatus in 2004. Snakes in the genus Lampropeltis are known to consume reptiles and reptilian eggs (Trauth and McAllister 1995). Although we have no data to support this conclusion, it is a possibility that the presence of yearling-size Lampropeltis in 2004 may have resulted in an absence of $P$. guttatus from this site. No kingsnakes were documented from the site in 2003. The early emergence record for P. guttatus, 28 March, provides very limited evidence that this species may utilize burrows made by rodents, especially Pine Voles, beneath pieces of metal as over-wintering sites.

The bimodal peak in observations of $P$. guttatus in this study corresponds to the spring/fall activity peaks documented for snakes in prior studies (e.g., Gibbons and Semlitsch 1987, Krysko 2002). These observations, with the exceptions of dead on road (DOR) individuals, likely demonstrate when this species came to the surface to utilize artificial cover and are not necessarily indicative of surface activity (e.g., foraging and movement). Although a bimodal activity pattern is less clear in our DOR observations, Gibson and Merkle (2004) found two distinct peaks in DOR snake collection in Powhatan County, Virginia: one in May/J une and another in September/October.

Previously reported reproductive observations for $P$. guttatus include clutch sizes of 11 (Florida; MacMahon 1957), 12 (Maryland; Groves 1957), 13 and 19 (North Carolina; Funk 1962), and 45 clutches with an average size of 12.7 (North Carolina; Palmer and Braswell 1995). The clutch sizes in Kentucky for five females ranged from 9 to 14 eggs with a mean clutch size of 10.8. Although the collection of gravid females indicated successful mating in this population, the absence of individuals on the low end of the size-class distribution (Figure 5) warrants discussion. It is possible that juvenile P. guttatus occupy different habitats (e.g., do not use artificial cover), or behaviorally vary from larger $P$. guttatus, making them difficult to detect using standard herpetological survey techniques. It follows that road-cruising activities are more likely to detect larger DOR snakes since smaller size classes are more likely to be overlooked. Alternately, the absence of these size classes may indicate that recruitment is occurring at low levels for this population. We suggest continued monitoring of $\mathrm{P}$. guttatus populations in Kentucky to determine the cause of these missing size classes.

The results of our morphological assessments support existing hypotheses of geographic structure within P. guttatus. In his work on geographic variation in this species, Mitchell (1977) examined 18 sample localities ranging from New Jersey in the north to the Florida Keys in the south and noted a clinal decrease in the mean number of dorsal body blotches from the north to the south. Our results support Mitchell's hypothesis since the dorsal body blotch mean for Kentucky P. guttatus most closely resembled Mitchell's Maryland sample locality. The Maryland locality differs from our Kentucky localities by only one degree of latitude. Mitchell (1977) also reported weak north-to-south clinal variation in the number of ventral scales and subcaudal scales, where northern counts tended to be fewer than southern ones. In addition, Thomas (1974) observed P. guttatus west of the Mississippi River with incomplete spear-point markings, but speculated that a complete spear-point was a characteristic of populations east of the Mississippi River. Our results were consistent with Thomas' position since, of the more than 100 total individuals we observed in Kentucky, only 3 did not have the classic spear-point marking. Mitchell (1977) was the first to suggest that females are characterized by fewer subcaudals than males. Our results are consistent with these hypotheses and it is very likely that subcaudal scale sexual dimorphism exists throughout the range of P. guttatus. P. guttatus in Kentucky, though disjunct from other populations, have maintained clinal meristic characteristics and sexual dimorphism consistent with other portions of the species range.

Although range-wide meristic variation is evident from this study and the work of Mitchell (1977) and Thomas (1974), the interpretation of these results in the context of ongoing taxonomic debates is not clear. It is becoming favorable to base phylogenetic hypotheses on more than one factor; for example, incorporating adaptive, morphological, and genetic variation (Avise 2004). Assessing meristics, as well as the ecological niche of Pituophis in the context of the known information for Pantherophis may facilitate a deeper understanding of the relationships between these taxa. This is especially important since many biologists believe current taxonomy does not reflect the biodiversity in need of protection (Pennock and Dimmick 1997). Before combining genera (e.g., Pantherophis placed within Pituophis), it is important to assess variation on more than one scale. By taking ecological, meristic, and genetic information into account, P. guttatus may ultimately be placed in the appropriate taxonomic category which would be useful in a conservation and management context.

We acknowledge that the largest flaw in our study is the lack of documentation of total effort using each sampling technique across years. Although we did not record total road searching hours, total man-hours, or total trap nights, we are confident that our search efforts were consistent across years of this study. Despite this oversight, the natural history and meristic information from these 101 P. guttatus, representing an isolated population, is valuable in both a conservation and natural history context.

\section{ACKNOWLEDGMENTS}

We thank Liz Davis and Sheila Peak for their unwavering support. We thank J. Harrison, J. Hohman, and J. MacGregor for sharing locality data. We are particularly grateful to J. Seymour, R. Seymour, J. Austin, her late husband Bill, and to T. Smith for allowing us access to 
their properties. We thank the entire staff of Touchstone Energy Cooperation for providing us with equipment. We thank J.D. Wilson for permission to use his range map. We thank D. Taylor, E. Greenbaum, R. Reed, K. Krysko, and two anonymous reviewers for comments on an earlier draft of this manuscript. We also thank Clovis for liberating our truck from the mud on multiple occasions.

\section{LITERATURE CITED}

Avise, J.C. 2004. Molecular Markers, Natural History, and Evolution. Sinauer Associates, Inc. Publishers, Sunderland, MA. $541 \mathrm{pp}$.

Burbrink, F.T. 2002. Phylogeographic analysis of the cornsnake (Elaphe guttata) complex as inferred from maximum likelihood and Bayesian analyses. Molecular Phylogenetics and Evolution 25:465-476.

Burbrink, F.T., and R. Lawson. 2007. How and when did old world ratsnakes disperse into the new world? Molecular Phylogenetics and Evolution 43: 173-189.

Burgdorf, S.J., C.D. Rudolph, R.N. Conner, D. Saenz, R.R. Schaefer. 2005. A successful trap design for capturing large terrestrial snakes. Herpetological Review 36: $421-424$.

Campbell, H.W., and S.P. Christman. 1982. Field techniques for herpetofaunal community analysis. Pp. 193-200, In N. Scott, Jr. (Ed.). Herpetological Communities. U.S. Fish and Wildlife Service, Wildlife Research Report 13, Washington, D.C.

Chenoweth, W.L. 1949. Elaphe guttata in South-Central Kentucky. Herpetologica 5:22.

Collins, J.T. 1970. The Corn Snake, Elaphe guttata guttata (Linnaeus) in Kentucky. Transactions of the Kentucky Academy of Science Volume 31.

Collins, J.T., and T.W. Taggart. 2008. An alternative classification of the new world rat snakes (Genus Pantherophis [Reptilia: Squamata: Colubridae]). Journal of Kansas Herpetology 26: 16-18.

Conant, R. and J.T. Collins. 1998. A Field Guide to the Amphibians and Reptiles of Eastern and Central North America, $3^{\text {rd }}$ Edition, Houghton Mifflin Company, Boston, Massachusetts, $616 \mathrm{pp}$.

Dowling, H.G. 1951. A taxonomic study of the American representatives of the genus Elaphe Fitzinger, with particular attention to the forms occurring in Mexico and Central America. Ph.D. Dissertation. University of Michigan, Ann Arbor, MI. 234 pp.

Enge, K.M., and K.N. Wood. 2002. A pedestrian road survey of an upland snake community in Florida. Southeastern Naturalist 4:365-380.

Fitch, H.S. 1987. Collecting and life-history techniques. Pp. 143-181, In R. Seigel, J. Collins and S. Novak (Eds.). Snakes: Ecology and Evolutionary Biology, McGraw-Hill, New York. 543 pp.

Funk, R.S. 1962. On the reproduction of Elaphe g. guttata (Linnaeus). Herpetologica 18:66.

Gibbons, J.W., and R.D. Semlitsch. 1981. Terrestrial drift fences with pitfall traps: An effective technique for quantitative sampling of animal populations. Brimleyana 7:1-16.

Gibbons, J.W., and R.D. Semlitsch. 1987. Activity patterns. Pp. 396-421, In R. Seigel, J. Collins and S. Novak (Eds.). Snakes: Ecology and Evolutionary Biology, McGraw-Hill, New York. 543 pp.

Gibson, J.D., and D.A. Merkle. 2004. Road mortality of snakes in central Virginia. Banisteria 24:8-14.

Groves, F. 1957. Eggs and young of the Corn Snake in
Maryland. Herpetologica 13:79-80.

Hibbard, C.W. 1936. The amphibians and reptiles of Mammoth Cave National Park. Transactions of the Kansas Academy of Sciences 29:277-281.

Holtzman, D.A., T.W. Harris, G. Aranguren, and E. Bostock. 1999. Spatial learning of an escape task by young corn snakes, Elaphe guttata guttata. Animal Behavior 57:51-60.

Kentucky's Comprehensive Wildlife Conservation Strategy. 2005. Kentucky Department of Fish and Wildlife Resources, \#1 Sportsman's Lane, Frankfort, Kentucky 40601. http://fw.ky.gov/kfwis/stwg/ (Date updated 9/21/2005)

Krysko, K. 2002. Seasonal activity of the Florida kingsnake Lampropeltis getula floridana (Serpentes: Colubridae) in southern Florida. American Midland Naturalist. 148: 102-114.

MacMahon, J.A. 1957. Observations on mating in the Corn Snake, Elaphe guttata guttata. Copeia 1957:232.

Meade, L.E. 2005. Kentucky Snakes, Their Identification, Variation, and Distribution. Kentucky State Nature Preserves Commission, Frankfort, KY. 323 pp.

Mitchell, J.C. 1977. Geographic variation of Elaphe guttata (Reptilia: Serpentes) in the Atlantic Coastal Plain. Copeia 1977:33-41.

NatureServe. 2008. NatureServe Explorer: An online encyclopedia of life (web application). Version 7.0. NatureServe, Arlington, Virginia. Available http:// www. natureserve.org/explorer. (Accessed: October 22, 2009).

National Oceanic and Atmospheric Administration/National Weather Services Forecast Offices. 2005. Selected U.S. City and State Extremes. (http://www. ncdc. noaa.gov/oa/climate/research/2004/sep/septemberext2004.html). 16 J anuary 2010.

Palmer, W.M., and A.L. Braswell. 1995. Reptiles of North Carolina. University of North Carolina Press, Chapel Hill. 412 pp.

Pennock, D.S., and W.W. Dimmick. 1997. Critique of the evolutionarily significant unit as a definition for distinct population segments under the U.S. Endangered Species Act. Conservation Biology 11:611619.

Smith, G.C. 1976. Ecological energetics of three species of ectothermic vertebrates. Ecology 57:252-264.

Thomas, R.A. 1974. Geographic variation in Elaphe guttata (Linnaeus) (Serpentes: Colubridae). M.S. Thesis. Texas A\&M University, College Station, Texas.

Todd, R.E. 1976. Geographic distribution: Elaphe guttata guttata. Herpetological Review 7:178.

Trauth, S.E., and C.T. McAllister. 1995. Vertebrate prey of selected Arkansas snakes. Proceedings of the Arkansas Academy of Science 49: 188-192.

Tuberville, T.D., J.D. Willson, M.E. Dorcas, and J.W. Gibbons. 2005. Herpetofaunal species richness of southeastern national parks. Southeastern Naturalist 4:537-569.

Utiger, U., N. Helfenberger, B. Schatti, C. Schmidt, M. Ruf, and V. Ziswiler. 2002. Molecular systematics and phylogeny of Old and New World ratsnakes, Elaphe Auct, and related genera (Reptilia, Squamata, Colubridae). Russian J ournal of Herpetology 9: 105-124.

Weldon, P.J., N.B. Ford, and J.J. Perry-Richardson. 1989. Responses by corn snakes (Elaphe guttata) to chemicals from heterospecific snakes. Journal of Chemical Ecology 16:37-44. 